\title{
Sport Injury and College Athlete Health Across the Lifespan
}

\author{
Diane M. Wiese-Bjornstal \\ University of Minnesota
}

What is the price of sports participation? The recently released Physical Activity Guidelines for Americans Advisory Committee Report (United States Department of Health \& Human Services [USDHHS], 2008) refers to sport injury as one of the prices, or "adverse events," associated with regular physical activity such as competitive sport participation. Evidence in the colloquium paper presented by Zernicke, Antle, McLean, Palmieri-Smith, Miller, and Wojtys (2009)—entitled Play at Your Own Risk: Sport and the Injury Epidemic - demonstrates the magnitude and extent of this sport injury price, and provides a comprehensive and multifaceted look at both the nature of the problem and cutting edge, research-based solutions. As a reactor to their paper, my frames of reference include those of a (a) scholar in sport and exercise psychology with specific expertise in the psychology of sport injury, (b) former intercollegiate athlete who sustained many sport injuries herself, and, (c) former intercollegiate coach who dealt on the front lines with numerous athletes incurring and recovering from sport injuries.

Is excellence in sport compatible with good health? Within the specific context of intercollegiate sport injury, my answer to this question relates to two salient themes that emerged for me in reaction to Zernicke et al.'s (2009) paper: first, that one must consider multiple dimensions of athlete health to fully grasp the compatibility of excellence and health, and second, that one must consider the full lifespan of intercollegiate athletes when answering the question.

First, with respect to multiple dimensions, some of the key dimensions of athlete health affected by sport injury include physical (e.g., general health and functioning, orthopedic health, sport performance), social (e.g., ability to interact with other individuals), cognitive (e.g., ability to process information and act properly), emotional (e.g., ability to cope, adjust, and adapt), spiritual (e.g., belief in some force or dynamic other than humans), philosophical (e.g., the belief system that governs engagement), and economic (e.g., financial livelihood and support for activities). Furthermore, in addition to sport injury affecting multiple dimensions of the injured athlete's own health, there is the health of the broader system to consider. Injury affects more than the injured; it often also holds healthrelated consequences for the network of family, friends, teammates, coaching

The author is with the School of Kinesiology, Cooke Hall, University of Minnesota, 1900 University Ave SE, Minneapolis, MN 55455. 
staff and even the larger communities, all who rely in some way on the healthy presence and performance of these athletes for their own well-being. For example, I have receive many searching - and often nearly desperate-e-mail and phone contacts from parents of injured athletes, so troubled themselves to see their child suffering the gamut of health-related consequences that they in turn are overwhelmed and unhealthy and seeking advice as to how to assist their young person. Therefore, my point is that in many ways sport injury affects both the multidimensional "internal" health of the injured athlete, as well as the multidimensional "external" health of the system surrounding them.

Second, adopting a lifespan view means considering these multidimensional, health-related implications of sport injury across the entire life cycle of the intercollegiate athlete (see Figure 1). For example, many of the lifespan issues related to sport injury occur even before intercollegiate participation. In a macro-systemic health sense, the entire youth sport culture in today's society is unfortunately all too often one of excess and a willingness to sacrifice health-physical, psychological, social — in a misguided attempt to achieve the ultimate dream of a college scholarship and perhaps even a professional contract. As evidenced by many recent popular press publications on the topic (e.g., Farrey, 2008; Sokolove, 2008), parents, coaches, and other social influences on impressionable young athletes push the extremes of participation for their kids in a quest for fame, glory and wealth, often with unfortunate consequences for health. But other recent popular publications (e.g., Gladwell, 2008) remind us that there is also an extraordinary amount of luck and good fortune-being in the right place at the right time, so to speak-involved in most areas of success in life, including sports. So to be willing to sacrifice the good health of young, vulnerable athletes (whether they want it for themselves; oftentimes even they do not know) in the sole hopes of creating the future college champion is dangerous and saddening. And many other such books and publications (e.g., Nowinski, 2006; Sokolove, 2008) illustrate for us the longterm, postcollege consequences of a "do or die" attitude embracing the normative sport ethic - ingrained in athletes from the youngest of ages: to play with pain,

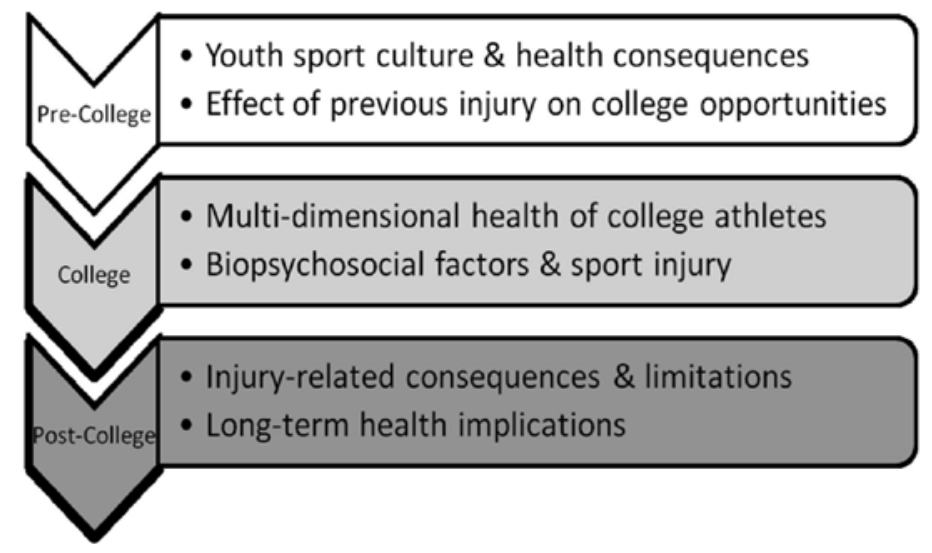

Figure 1 - Chronology of sport injury and health across the lifespan. 
injury, and in general to sacrifice one's body in the name of the game (Hughes \& Coakley, 1997; Wiese-Bjornstal, 2000; 2002a, 2002b; Wiese-Bjornstal, Smith, Schaffer, \& Morrey, 1998).

In a microsystemic sense, engagement in this very driven youth sport culture means that long before athletes even get to intercollegiate participation, many experience at least one and, unfortunately for many young athletes, multiple sport injuries. Some of these young athletes recover sufficiently to be able to pursue intercollegiate participation, but many never even get to the point of choosing whether to participate due to their previous injuries. Therefore, these huge losses of potential reduced in some ways the intercollegiate pool of talent. For those that are injured as young athletes but still make it to college, they may carry the negative health-related consequences of these early years through their college experiences as well.

At the college level and beyond, the obvious dimension of health affected by sport injury is physical health, but evidence shows us that the impact is often far more reaching that that. I will discuss some specific examples of these "health across the lifespan" considerations later in the paper. The key point for now is that in thinking about how sport injury affects college athletes, it becomes important to investigate the multidimensional aspects of health described earlier to understand fully the implications. So for researchers such as Zernicke et al. (2009) and Silvers (2009) who conduct research on sport injury, it is essential that they continue to consider the complex combination of biopsychosocial factors that influence the incurrence of - and recovery from-sport injury.

\section{Four Reflections}

With these background considerations in mind, let me offer four specific reflections of mine concerning the evidence presented in Zernicke et al.'s (2009) paper. These reflections will be followed by some specific implications and recommendations derived from these reflections for National Collegiate Athletic Association (NCAA) staff and affiliated programs, coaches, and personnel to consider relative to sport injury and the health of college athletes across the lifespan.

\section{Reflection \#1: Integrate a Psychology Perspective}

Zernicke et al. (2009) were quite comprehensive in their approach to sport injury causes and consequences. Psychological factors, however, are also part of this complex combination of factors that make up a sport injury "profile," if you will (Wiese-Bjornstal, 2003, 2004). Therefore, I would like to flesh out a bit more the psychology perspective on sport injury as an integral part of the whole picture. For example, before an injury a multitude of factors affects an athlete's vulnerability, susceptibility, or predisposition (see Figure 2). Although the proximate cause of injury is not psychological factors per se, much evidence leads us to conclude that psychological factors, in concert with other factors, contribute to risk profiles that should concern those who make up athletes' support systems. As illustrated by the examples in the figure, a complex combination of factors contributes to each athlete's personal sport injury risk profile. In any given sport situation, therefore, an athlete might be more or less at risk depending on the interaction between his or 


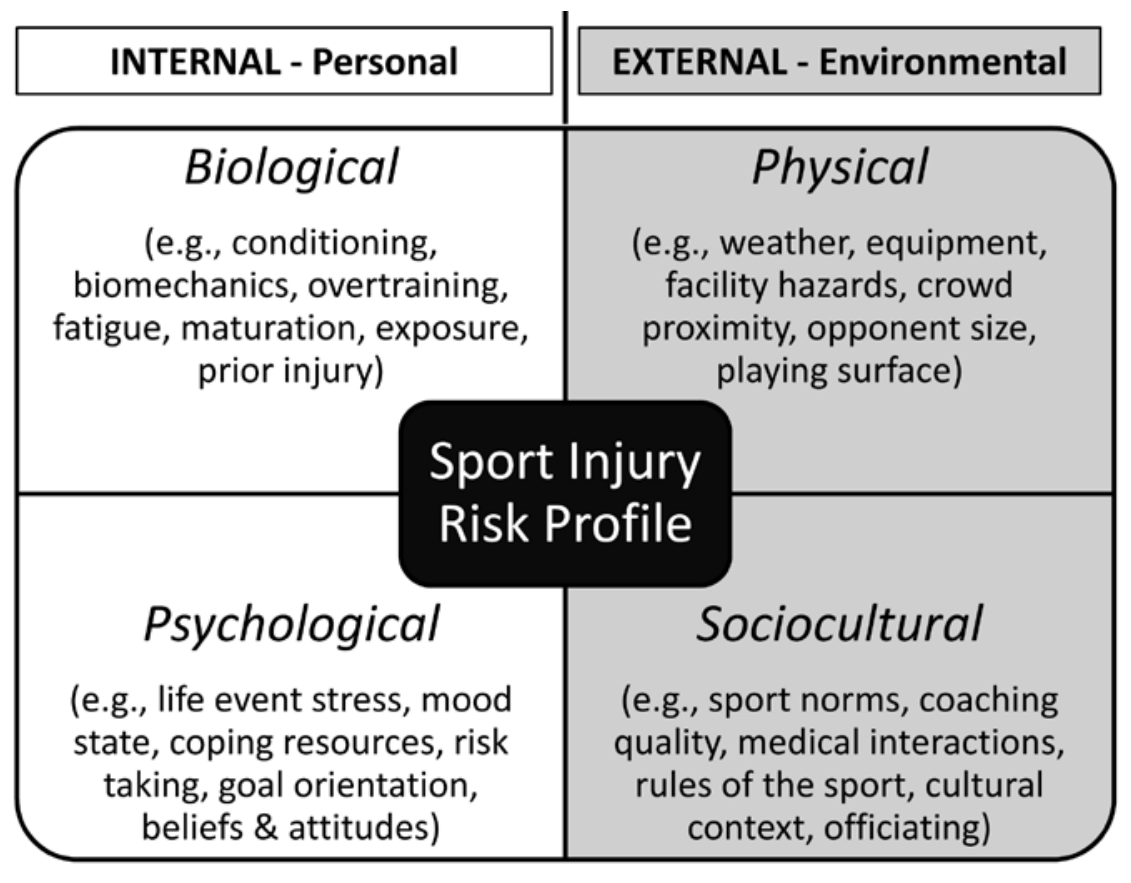

Figure 2 - Sport injury risk profile.

her personal characteristics and status and the profile of risks or protections offered by the physical and sociocultural environment of that situation.

Figure 2 provides some illustrations of how psychology confirms the dangers of these risk factors. One of the most consistent findings in the preinjury psychological vulnerabilities (Williams \& Andersen, 1998) literature surrounds life event stress. Major life-event stress (defined as the perceived strain associated with major life events such as starting at a new school, death of a family member, divorce of parents, moving homes, getting married, relationship breakup) and, in particular, negative life-event stress (the self-rated negative impact of these major events on personal stress levels), in most studies to date is predictive of sport injury occurrence. As a result, athletes who self-report experiencing higher levels of stress associated with major life events are more likely to sustain a sport injury than those who report lower levels. This is particularly true if these athletes also self-report low coping skills or few social resources to deal with the stress. For example, one of our early studies of NCAA Division III football players showed that athletes who experienced higher levels of life-event stress were more likely to have been injured in the course of a season (Luo, 1994). In another study, involving NCAA Division I intercollegiate athletes (Wiese-Bjornstal, Heniff, \& Henert, 1998), we found that those athletes who sustained a sport injury self-reported major life event stress levels at the beginning of the season that were twice that of their uninjured teammates. In this same study, we also found that these injured athletes were more negative in their mood state before, during, and after the injury 
than were their uninjured counterparts on the same teams. Similarly, work with male high school hockey players (Smith, Stuart, Wiese-Bjornstal, \& Gunnon, 1997) showed us that preseason mood state, particularly fatigue, was predictive of sport injury during the competitive season.

In the postinjury phase (Wiese-Bjornstal, Smith, \& LaMott, 1995), mood state is an example of a psychological factor that varies in relation to the time required for recovery. The temporal flow, as depicted in Figure 3, shows characteristics that, over the sport injury lifespan from incurrence to return to play, illustrate continuous overlapping phases of postinjury reaction, response, adjustment, and return. This sort of pattern is reflected in our postinjury response mood-state data from two independent doctoral dissertations examining responses to anterior cruciate ligament (ACL) injury (LaMott, 1994; Morrey, Stuart, Smith, \& WieseBjornstal, 1999; Wiese-Bjornstal, 2001). These studies showed curvilinear temporal responses among mood states, referred to by LaMott as the "Emotional U." Athletes exhibited negative moods during the more reactive presurgical operation through postoperation period; they then became increasingly less negative in their responses during the intermediate weeks, which reflected some level of adjustment. As they approached and entered the return-to-sport phase, however, the athletes became increasingly negative. In other words, mood state, as one indicator of psychological response to injury is not static but is rather quite dynamic. These negative mood states have implications for many aspects of health, including wound healing, which is affected by athlete stress and emotion through psychoneuroimmunological pathways (Glaser \& Kiecolt-Glaser, 2005).

In addition, although sport participation is often the cause of injury-and the associated negative health consequences-let us not forget that it can also be the way back to health. For physically active people, one of the most psychologically beneficial things postinjury is to figure out what kinds of physical activities they can do (such as cross training, working uninjured body parts), and get them doing them. This is invaluable to their mental health, and for many, even a form of salvation. Consider the case of wounded military personnel operating in a military culture that is in many ways similar to sport. For active and athletic soldiers injured in battle and faced with what might seem to be discouraging prospects for the future, engaging in running, basketball, or other forms of sport activities and competitive athletics is a saving grace to their mental, physical, and spiritual

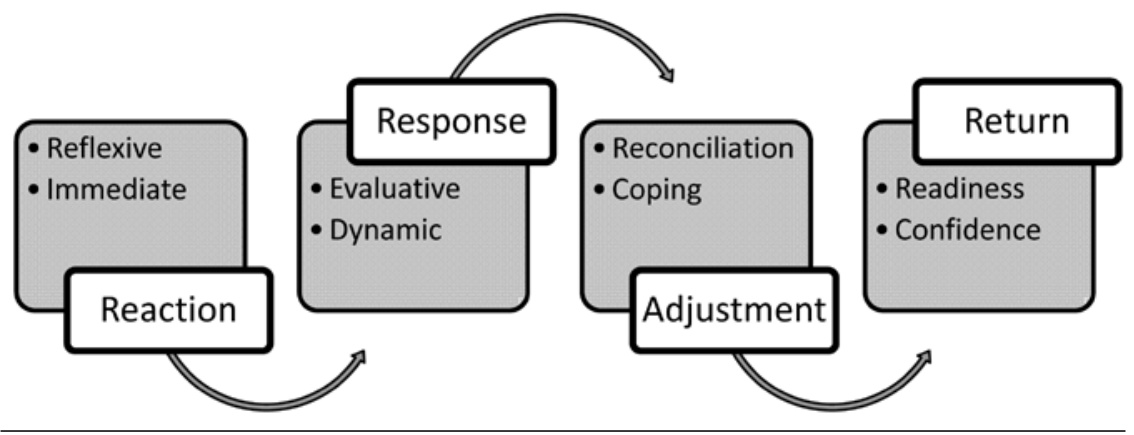

Figure 3 - Temporal flow of sport injury lifespan. 
health (Bembry, 2004; Price, 2005). This same concept is important to injured athletes, who also sometimes seem to view their future athletic participation prospects as hopeless and disheartening. Therefore, physical activity should be an integral part of the return-to-health plan for injured athletes. In sum, with respect to reflection \#1, I hope I have convinced you that it is important to consider the role of psychological factors on sport injury causes and consequences.

\section{Reflection \#2: Consider Multidimensional Lifespan Health}

In the previous section, I talked about the importance of considering psychological factors across the full "lifespan" of a specific sport injury, from incurrence to return-to-play. We now consider the full "lifespan" of intercollegiate athletes themselves (Wiese-Bjornstal, 2003), from the time before they even get to college (as discussed in the introduction) through the college years, and continuing across their postcollege adult years. Furthermore, returning to our discussion of the multiple dimensions of health, if we bring together these two themes we might end up with a grid that looks something like that in Table 1. Pulling a few examples of these multiple dimensions of health considerations from the Zernicke et al. (2009) paper, and inserting them into relevant or corresponding cells in the table grid by aspect of athlete lifespan, we can begin to see how complicated, and yet how very important, it is to think about these two intersecting dimensions. That is to say, it becomes very clear to us that sport injury is not about a specific, isolated time and place incident, but that its adverse impact is often wide ranging and far reaching. It reinforces Zernicke et al.'s contention that "complex problems demand complex solutions."

Intercollegiate athletes cite injury as one of the most stressful factors related to their athletic participation (Selby, Weinstein, \& Bird, 1990). Serious injury has been shown to be a negative influence on health status, for example, including undesirable effects on such areas as self-reported behavioral functioning, subjective well-being, perceptions of overall health, and physical and mental health status (McAllister, Motamedi, Hame, Shapiro, \& Dorey, 2001).

For more detail on a specific example, look at Table 1 for research results on the long-term physical consequences of intercollegiate sport injuries. Data from a variety of sources suggests that the long-term effects of sports-related orthopedic injuries on athletes are more significant than those experienced by nonathletes. A survey of alumni intercollegiate athletes with nonathlete controls from the same university done by Friery and Bishop (2007) showed that 50\% of athletes had major injuries in college (compared with only $10 \%$ of controls), $52 \%$ of former athletes reported chronic injuries postcollege (compared with $11 \%$ of controls), and $36 \%$ of former athletes reported limitations during exercise (compared with $4 \%$ of controls). As described in Sports Illustrated (as cited in Nack \& Munson, 2001), in a 1990 Ball State Study that covered 50 years of National Football League (NFL) history, researchers found that among 870 former NFL players, $65 \%$ had suffered a "major injury" while playing. Such players increased from $42 \%$ before 1959 to $72 \%$ in the 1980 s. Two of three former players disclosed that football injuries had limited their sport and recreation choices postretirement. Of players from the 1970s and 1980s, nearly half reported that they had retired because of injury. Among women who no longer participated in their collegiate 


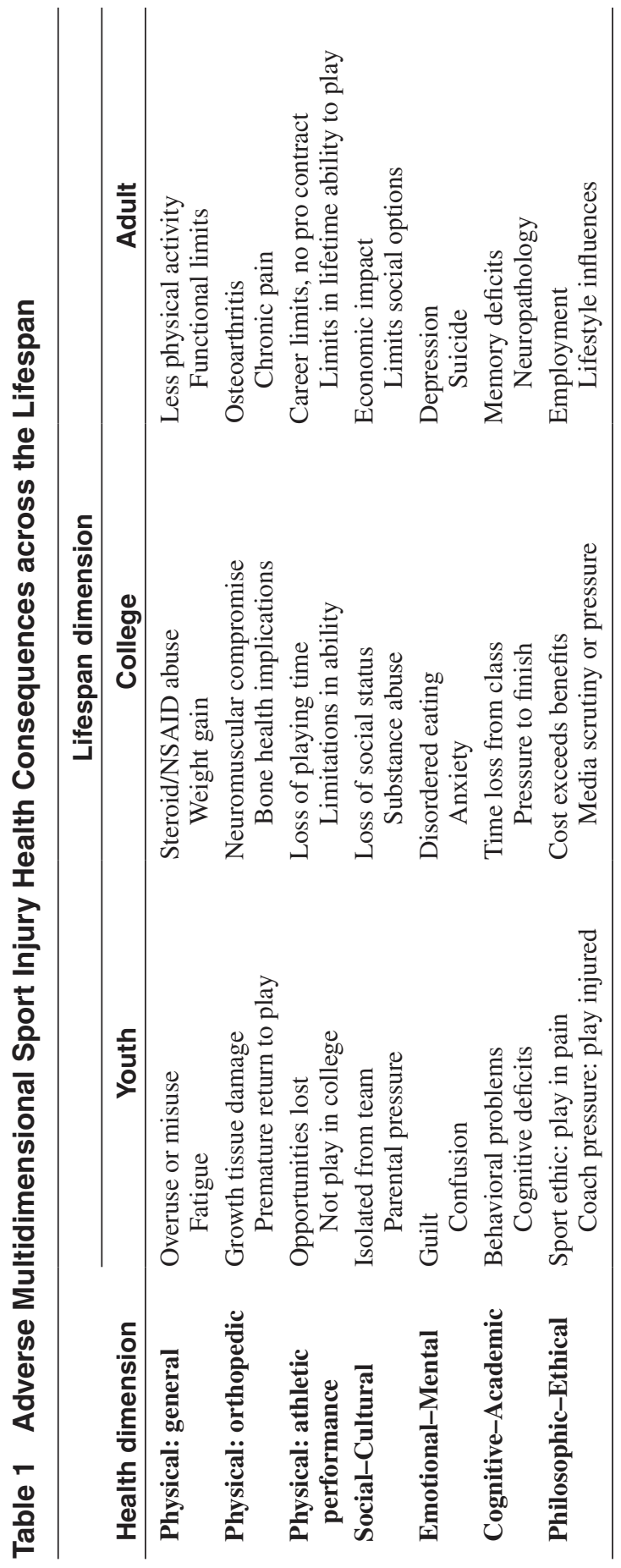


sport after college, $27 \%$ reported that they did not participate because of musculoskeletal problems (Strawbridge, 2001), although the researcher did not report whether these musculoskeletal problems related directly to collegiate athletic participation. Studies of former professional soccer players demonstrate that the long-term effects of their participation include osteoarthritis and musculoskeletal pain that influenced health-related quality of life long after their playing days are over (Turner, Barlow, \& Heathcote-Elliott, 2000).

A reminder is in order, here, that sport injury can also, in a "making the best out of a bad situation" kind of way, lead to positive outcomes for athletes. Many athletes indicate they would prefer to avoid injury but also mention that injuries can be a blessing in disguise because they can provide opportunities to reflect on priorities, recall how much they enjoyed sport, renew their motivation and commitment, learn new skills, and not to take anything for granted, including good health. In teaching a Psychology of Sport Injury class for many years, one of my assignments involves students reporting on their own sport injury experiences (typically those sustained during their youth athlete years) and the physical, psychological, and social aspects of those experiences. It is just astonishing to read such personal stories of the negative and long term impact of these injuries on so many of these young people. It is the norm, not the exception, unfortunately. The encouraging side, however, is that they think and write about the "positives" that came out of their injury experiences, and I am always reminded how truly resilient most athletes are and how they can, in retrospect, find the silver lining. Things such as broadening their identities during their recovery period, considering careers in health and medicine so that they can help others in similar situations, or redirecting energies and passions to different sports are among the items mentioned. Therefore, to understand both the short- and long-term consequences of sport injury on intercollegiate athlete health, one must take a multidisciplinary lifespan view, as well as one that considers not only the adverse outcomes but the positive ones as well.

\section{Reflection \#3: Acknowledge Gender and Individual Differences}

Because I am a part of the Tucker Center for Research on Girls \& Women in Sport at the University of Minnesota, I feel it appropriate to comment on the intersection between sport injury and gender. These themes are evident in Zernicke et al.'s (2009) presentations, and furthermore, as a parent of both a son and a daughter, I have considered gender and its relationship to sport injury. Therefore, I will answer his call for "influential female leaders" to raise and address issues related to sport injury and female athlete health. As I write this, I am watching, for the second day in row, my teenage daughter and her volleyball team participate in a tournament that involves hundreds of girls' teams playing thousands of matches throughout our metropolitan area. I have watched scores of matches over the past 24 hours, with many more yet to go before the day is through, and I have thankfully yet to see any injuries that have caused an athlete to miss any action whatsoever. I do see a few ankle and knee braces and taped fingers, but for the most part, they seem to be healthy, strong, lively, and energetic young women. In other words, even though sport injury is a significant health problem for females, we 
must remember that the health benefits of sports participation in most cases far exceed the health costs.

When costs occur, however, they can be significant, and so I support Zernicke et al. (2009) and Silvers (2009) contention that we need to do our utmost to prevent sport injury and, if it does happen, to help athletes recover. Moreover, I think it is appropriate to target females or other demographic groups with interventions based on their own unique needs and challenges. This is one of the themes of the book Warrior Girls (Sokolove, 2008), mentioned by Zernicke et al. in their article. My one major point of digression with Sokolove, however, is that although sport injury is just as much a concern for male as female athletes, but this does not discount the fact that sport injury is indeed a problem for female athletes (WieseBjornstal, 2008).

Furthermore, in response to Zernicke et al. (2009) and Sokolove (2008), I would say that gender is but one of many different factors that affect injury risk and response (revisit Figure 2), and to either focus on it exclusively or emphasize it over other factors would be misleading. Take the case of knee injuries, for example, which are the central focus of the Warrior Girls book and Zernicke et al.'s paper. As a "public health" problem, knee injuries are more common among male athletes than they are among female athletes when not controlling for exposure (e.g., see the National Electronic Injury Surveillance System online, 2009), albeit less commonly of the noncontact causality mechanism. From a sheer magnitude standpoint, therefore, one should argue that we should be more worried about males than females. But the difference is that there are certain sports-contact sports in particular, such as football-that are largely responsible for the rash of knee injuries among males (Shankar, Fields, Collins, Dick, \& Comstock, 2007). Yet one does not hear the outcry against football, either demanding its elimination or raising the rallying cry that we must protect our boys. The alarm is raised by some that females' greater incidence of noncontact knee injuries is evidence that girls are not really meant to play sports or that they must be protected because of their vulnerabilities (Anantomy Isn't Destiny, 2008).

Both males and females, however, have to face the challenges presented by knee injuries. In the 2001 health survey of retired NFL players (Center for the Study of Retired Athletes, 2008), for example, among over 2500 surveys returned, $20 \%$ "reported sustaining at least once ACL injury during their professional playing years" (p. 2). Furthermore, the survey showed that the number of ACL and medial collateral ligament (MCL) ruptures has "increased exponentially" for the past several decades. In a survey of former collegiate athletes (Friery \& Bishop, 2007), former athletes from power events (i.e., men's football, women's gymnastics, and men's and women's track and field sprinting and field events) reported disability related to orthopedic events in the postcollege life more frequently than did other athletes or nonathlete controls.

Therefore, I am in agreement with Silvers (2009), Sokolove (2008), and Zernicke et al. (2009) that we should continue to explore interventions with female athletes to prevent injury by changing the dominant philosophy of excess in youth sport, by promoting targeted conditioning programs for individual athletes, and by educating parents and athletes about "healthy" and effective sport participation. We should also be tailoring programs to the unique needs of a wide variety of 
other athletes based on individual differences, sport type, and position played. Clearly, for both sexes sport injuries are a significant health problem.

\section{Reflection \#4: Attend to Mental Health}

Seeing the popular press magazines around the time of the 2008 Summer Olympics-such as Popular Science's Special Issue: The Science of Sports (2008), and Discover Presents: The Body (2008)_fascinated me with the latest scientific evidence about how to build prototype athletes and maximize sport performance at the highest of levels. I also admit to being concerned that we are trying to build "machines" instead of people. I am reminded that what sets us apart from machines are our minds, souls, and spirits, and the social and communal nature in which we live and perform. In the broadest sense, intercollegiate sport participation is a voluntary leisure experience with defining characteristics related to physical health (e.g., physical fitness, regular exercise), mental health (e.g., intrinsic motivation, choice, self-determination, and enjoyment), and social health (e.g., camaraderie, civic engagement)(Kimball \& Freysinger, 2003). Being an intercollegiate athlete involves elements of both eustress (good, or healthy stress), from challenge, mastery, intrinsic motivation, and camaraderie, and distress (harmful, or unhealthy, stress) from sources such as injury, poor performance, controlling coaches, lack of control over schedules and conflicting demands, and race, gender, and social-class expectations related to athlete status (Kimball \& Freysinger, 2003). The ability to balance these experiences of distress and eustress while maintaining good mental, physical, and social health depends on the social resources and personal coping abilities available to athletes.

For example, the mental health status of college-age students in general, and athletes in specific, has becoming of increasing concern in recent years amid rising rates of clinical diagnoses. Mental health care often falls under the domain of sports medicine in university athletics departments, and yet there is often limited comfort among sports medicine personnel with addressing mental health issues. The intercollegiate athletics culture can be inhibiting to mental health care (Hosick, 2005) in part because of history and tradition. Mental wellness is not always perceived as necessary for athletic performance, and the high profile of student-athletes may magnify unwanted attention paid to them when they seek help. Athletics departments may also desire to dissociate mental illness with athletic participation at their institutions to present themselves in the best possible light.

Literature would suggest that the mental health needs of college athletes relate to at least four domains: mental health problems, eating problems, risk behaviors, and performance pressure (Steiner, Pyle, Brassington, Matheson, \& King, 2003). With respect to mental health problems, disorders of mood and personality and psychopathology are thought to be present among athletes in proportions similar to or greater than their nonathlete counterparts (Brewer \& Petrie, 1996). Self-reported pathology, including social anxiety and depressive symptoms, has been found to be higher among collegiate female athletes than among male athletes or male and female nonathletes (Storch, Storch, Killiany, \& Roberti, 2005; Yang, Peek-Asa, Corlette, Cheng, Foster, \& Albright, 2007). Athletes are underrepresented in their use of campus counseling services even 
though help-seeking behaviors such as using university counseling services are considered an adaptive mode of coping. Student-athletes, however, have less positive attitudes toward help-seeking behavior in general, fearing that they will be stigmatized or not understood (Watson, 2005).

Eating problems and pathogenic weight control behaviors cause physical and mental health concerns among intercollegiate athletes, particularly among females in lean sports (DePalma, Koszewski, Romani, Case, Zuiderhof, \& McCoy, 2002; Reinking \& Alexander, 2005; Sundgot-Borgen \& Torstveit, 2004). DiBartolo and Shaffer (2002), however, found that Division III female athletes in a variety of sports reported fewer eating-disorder symptoms and higher psychological wellbeing than nonathletes. Williamson, Netemeyer, Jackman, Anderson, Funsch, and Rabalais (1995) found that among university female athletes, eating disorder symptoms were influenced by a combination of "sociocultural pressure for thinness, athletic performance anxiety, and negative self-appraisal of athletic achievement" (p. 387). Interestingly, sport injury itself has been found to be a possible as a trigger for disordered eating (e.g., Sundgot-Borgen, 1994).

Higher levels of risk behaviors have been commonly reported in particular among male and contact sport collegiate student-athletes (Kokotailo, Henry, Koscik, Fleming, \& Landry, 1996). For example, university athletes have greater problem gambling rates than nonathletes (Engwall, Hunter, \& Steinberg, 2004), with males and NCAA Division III athletes more likely to report engaging in gambling or sports wagering behavior than females and Division I athletes (National Collegiate Athletic Association, 2003). A variety of risky substance use, including anabolic androgenic steroids, has been shown among college athletes (National Institute on Drug Abuse, 2000). Approximately 21\% of the college athlete population has been found to report high alcohol use associated with depression and psychiatric symptom ratings (Miller, Miller, Verhegge, Linville, \& Pumariega, 2002), with athletes and males more frequent consumers of alcohol than nonathletes and females (Wilson, Pritchard, \& Schaffer, 2004). Furthermore, there is some preliminary evidence of a link between alcohol consumption and sport injury (mentioned by Martens, Dams-O'Connor, \& Beck, 2006).

One of the ways in which athletes respond to performance pressure (Raglin, 2001) may be to get stronger or return faster by using banned substances; such use can often be related to sport injury recovery. For example, in 2001, of those intercollegiate athletes who reported using steroids, $16.7 \%$ indicated that the main reason that they used anabolic steroids was "sport injury", with another $11.5 \%$ saying that they used them for "non-sport injury" (National Collegiate Athletic Association, 2001). Small percentages of athletes also reported using amphetamines for the same reasons (2.6 and 3.9\% respectively). Of those using ephedrine, $5.9 \%$ used it primarily "to recover from injury." Other research suggests, however, that the physically active lifestyles and rigorous training needed to meet the performance standards of intercollegiate athletes are factors related to lower long-term risks of mental health concerns. In some cases athletes, for example, in general do report higher levels of well-being compared with nonathlete counterparts (Dworsky, 2005). Therefore, as is the case with the other reflections that we have examined, there clearly is both a good side and a bad side to the health implications of intercollegiate sport participation. 


\section{Practical Implications for NCAA}

With these reflections in mind, I next present some brief thoughts on practical implications or recommendations for the NCAA and other collegiate sportssponsoring entities relate to four major areas: screening, surveillance, studies, and services.

\section{Screening}

One idea for addressing other aspects of health, such as psychological health, would be to build more explicit psychological baseline measures into the preparticipation, preseason screenings that are done with respect to general health and orthopedics. For example, measures of major life event stress, mood state, fatigue, and depression could be completed at one of the stations for these preventative screenings. Some schools have tried this, including us, but it has not been as systematic in its implementation as would be advised. There are at least two major advantages to this. First, such screenings would provide the baseline for key psychological indicators, similar to neurocognitive testing baselines, so that changes in psychological states could be monitored and those that rise to a level of clinical concern could be addressed and dealt with more promptly and accurately. Second, such psychological data could also provide the baseline for prospective studies (A.M. Smith, personal communication, December 16, 2008). So broader, multidisciplinary psychological screening would be a good next step for NCAA schools to consider.

\section{Surveillance}

The NCAA Injury Surveillance System (ISS) has been a source of invaluable data on injuries in intercollegiate sport for many years (Dick, Agel, \& Marshall, 2007; Hootman, Dick, \& Agel, 2007). It was announced in the NCAA News (2009) that a new group, the Datalys Center for Sports Injury Research and Prevention, would soon have oversight over the NCAA ISS. Close colleagues that share my interests in the psychology of sport injury (e.g., A.M. Smith, personal communication, December 16, 2008) agree that the NCAA ISS would benefit from more prospective and systematic data collections surrounding psychological and social factors (among others), affecting injury risk and recovery. With the transition to a new system, it would seem the perfect opportunity to integrate additional or refined measures of variables like exposure, fatigue, injury causality, and long-term outcomes. This data would be critical to assess the impact of changes made to equipment, rules, social environment, and others on the occurrence and outcomes of sport injury. It would also allow the very complex, interdisciplinary research studies that are much needed. Furthermore, it would seem that a greater number of NCAA schools should participate in ISS data submission. The databases generated could then be as inclusive as possible, maximizing the benefits to athlete health through the knowledge gained. 


\section{Studies}

Following through on some of the examples given throughout the chapter and in the recommendations for screenings and surveillance, adopting prospective, lifespan focused, repeated measures, multidimensional health oriented elements in research projects would enhance our knowledge of the complex interplay in sport injury causality and consequence. Based on previous research on the relationships between intercollegiate sport participation and mental and physical health, we recommend examining individual and demographic difference such as gender, sport type, and level of competition as they relate to short- and long-term consequences for physical health, physical activity levels, general strength and cardiovascular fitness, orthopedic health, substance use, mental health, risk behaviors, mental health problems, academic performance, and other important health variables.

\section{Services}

Sport psychologists, among others offering services, should apply our expertise and skills to work in a variety of areas to better the health of student-athletes in relation to injury risk reduction and recovery. For example, those with expertise in behavior modification might use their skills to help athletes, coaches, and other sport personnel change modifiable risk factors, use protective equipment, and initiate other behavioral changes that are sometimes resisted within the sport culture. We can also use our skills to intervene both pre- and postinjury to help education, motivate, and rehabilitate injured athletes (c.f., Cupal, 1998; Perna, Antoni, Baum, Gordon, \& Schneiderman, 2003) through our use of traditional stress management, goal setting, and other psychological strategies. University athletics departments would be wise to make mental health services more accessible to their athletes, in the same way that they make available all kinds of physical health services. We find that often only cursory attention is paid to the importance of providing such mental health services, and yet clearly mental health is central to athlete performance and well-being. Finally, we could use our knowledge of education and motivation to help athletes and coaches embrace prevention programs such as those outlined by Silvers (2009).

\section{Summary}

Sports medicine and intercollegiate athletics share a common ground in recognizing the importance of caring for athlete health needs related to the stresses of sport participation and the special concerns related to sport injury. Yet there is an ethical challenge inherent in their intersection in that the demands of sport often conflict with the demands of health (Mathias, 2004). In other words, the most effective means of training for and competing in intercollegiate sport can be detrimental to athlete health — physical, mental, and social, short- and long-term-through the problems of excess, overuse, and misuse. The difficulty lies in the fact that although medical and sport professionals have at the core of their work the highest consideration for athlete health, there is a simultaneous responsibility to allow athlete autonomy in making health care decisions that affect their sporting lives 
and livelihood (Mathias, 2004), even when those decisions may jeopardize their health. Excellence in intercollegiate sport is compatible with good health, but that good health is dependent on the wisdom, expertise, and guidance of those responsible for creating and maintaining the sport opportunities and culture within which athletes participate. Even the "adverse event" of sport injury and its associated health costs, however, can be an opportunity to build health, through strength of character, resilience, and a desire to come back physically stronger than ever. In the words of Lindsay Whalen, former Minnesota Gophers basketball star and now Women's National Basketball Association (WNBA) player, "If it [injury] doesn't kill you, it will probably make you stronger, right? In the end, I will look at it as something you didn't want happening, but you get stronger from it" (Twincities. com, 2004, p. x).

\section{References}

Anatomy isn't destiny: A multidisciplinary response to Michael Sokolove's Warrior Girls. (2008, Fall). Tucker Center Newsletter. Retrieved February 15, 2009 from http://cehd. umn.edu/tuckercenter/newsletter/2008-fall/feature.htm

Bembry, J. (2004). A soldier's story. ESPN: The Magazine., 7(22), 96-100.

Brewer, B.W., \& Petrie, T.A. (1996). Psychopathology in sport and exercise. In J.L.Van Raalte (Ed.), Exploring sport and exercise psychology. Washington: American Psychological Association, p. 307-323.

Center for the Study of Retired Athletes. (2008). Initial findings from the 2001 health survey of retired National Football League (NFL) players. Retrieved November 6, 2008 from http://www.csra.unc.edu/statistics.htm

Cupal, D.D. (1998). Psychological interventions in sport injury prevention and rehabilitation. Journal of Applied Sport Psychology, 10(1), 103-123.

DePalma, M.T., Koszewski, W.M., Romani, W., Case, J.G., Zuiderhof, N.J., \& McCoy, P.M. (2002). Identifying college athletes at risk for pathogenic eating. British Journal of Sports Medicine, 36, 45-50.

DiBartolo, P.M., \& Shaffer, C. (2002). A comparison of female college athletes and nonathletes: Eating disorder symptomatology and psychological well-being. Journal of Sport \& Exercise Psychology, 24, 33-41.

Dick, R., Agel, J., \& Marshall, S. (2007). National Collegiate Athletic Association Injury surveillance system commentaries: Introduction and methods. Journal of Athletic Training, 42(2), 173-182.

Dworsky, D. (2005). Not as different as you might think: The psychosocial development of collegiate student-athletes and student-musicians. Dissertation Abstracts International Section B: The Sciences and Engineering. Vol. 65(9-B), 2005, 4825.

Engwall, D., Hunter, R., \& Steinberg, M. (2004). Gambling and other risk behaviors on university campuses. Journal of American College Health, 52, 245-255.

Farrey, T. (2008). Game on: The all-American race to make champions of our children. New York: ESPN Books.

Friery, K., \& Bishop, P. (2007). Long-term impact of athletic participation on physical capabilities. Journal of Exercise Physiology online, 10(1), 34-47.

Gladwell, M. (2008). Outliers: The story of success. New York: Little, Brown and Company.

Glaser, R., \& Kiecolt-Glaser, J.K. (2005). Stress-induced immune dysfunction: Implications for health. National Review, 5, 243-253. 
Hootman, J.M., Dick, R., \& Agel, J. (2007). Epidemiology of collegiate injuries for 15 sports: Summary and recommendations for injury prevention initiatives. Journal of Athletic Training, 42(2), 311-319.

Hosick, M.B. (2005, February 28). Forum places psychological focus on mental-health issues. NCAA News. Retrieved February 15, 2009 from http://www.ncaa.org/wps/ ncaa?ContentID $=31697$

Hughes, R.H., \& Coakley, J. (1991). Positive deviance among athletes: The implications of overconformity to the sport ethic. Sociology of Sport Journal, 8, 307-325.

Kimball, A., \& Freysinger, V.J. (2003). Leisure, stress, and coping: The sport participation of collegiate student-athletes. Leisure Sciences, 25, 115-141.

Kokotailo, P.K., Henry, B.C., Koscik, R.E., Fleming, M.F., \& Landry, G.L. (1996). Substance use and other health risk behaviors in college athletes. Clinical Journal of Sport Medicine, 6, 183-189.

LaMott, E.E. (1994). The anterior cruciate ligament injured athlete: The psychological process. Unpublished doctoral dissertation, University of Minnesota, Minneapolis.

Luo, Y. (1994). The relationship of daily hassles, major life events, and social support to athletic injury in football. Unpublished doctoral dissertation, University of Minnesota, Minneapolis.

Martens, M.P., Dams-O'Connor, K., \& Beck, N.C. (2006). A systematic review of college student-athlete drinking: Prevalence rates, sport-related factors, and interventions. Journal of Substance Abuse Treatment, 31, 305-316.

Mathias, M.B. (2004). The competing demands of sport and health: An essay on the history of ethics in sports medicine. Clinics in Sports Medicine, 23, 195-214.

McAllister, D.R., Motamedi, A.R., Hame, S.L., Shapiro, M.S., \& Dorey, F.J. (2001). Quality of Life assessment in elite collegiate athletes. American Journal of Sports Medicine, 29, 806-810.

Miller, B.E., Miller, M.N., Verhegge, R., Linville, H.H., \& Pumariega, A.J. (2002). Alcohol misuse among college athletes: Self-medication for psychiatric symptoms? Journal of Drug Education, 32, 41-52.

Morrey, M.A., Stuart, M.J., Smith, A.M., \& Wiese-Bjornstal, D.M. (1999). A longitudinal examination of athletes' emotional and cognitive response to anterior cruciate ligament injury. Clinical Journal of Sport Medicine, 9(2), 63-69.

Nack, W., \& Munson, L. (2001). The wrecking yard. Sports Illustrated, 94(19), 60-68.

National Collegiate Athletic Association. (2001). NCAA study of substance use habits of college student-athletes. Retrieved March 4, 2006 from http://www.ncaa.org/ research/

National Collegiate Athletic Association. (2003). NCAA national study on collegiate sports wagering and associated behaviors. Retrieved March 4, 2006 from http://www.ncaa. org/research/

National Electronic Injury Surveillance System (NEISS) online. (2008). Query NEISS by gender, sport, and knee injury. Retrieved February 15, 2009 from http://www.cpsc. gov/library/neiss.html

National Institute on Drug Abuse. (2000). Anabolic steroid abuse. Retrieved March 5, 2006 from http://www.nida.nih.gov/ResearchReports/Steroids/AnabolicSteroids.html

News, N.C.A.A. (2009). New group to administer NCAA Injury Surveillance System. Retrieved January 9, 2009 from http://www.ncaa.org/wps/wcm/connect/ $\mathrm{NCAA}+\mathrm{News}$

Nowinski, C. (2006). Head games: Football's concussion crisis. Boston: Drummond Publishing Group.

Perna, F.M., Antoni, M.H., Baum, A., Gordon, P., \& Schneiderman, N. (2003). Cognitive behavioral stress management effects on injury and illness among competitive athletes: A randomized clinical trial. Annals of Behavioral Medicine, 25(1), 66-73.

Price, S.L. (2005). Run to daylight. Sports Illustrated, 103(23), 112-120. 
Raglin, J.S. (2001). Psychological factors in sport performance: The mental health model revisited. Sports Medicine (Auckland, N.Z.), 31, 875-890.

Reinking, M.F., \& Alexander, L.W. (2005). Prevalence of disordered-eating behaviors in undergraduate female collegiate athletes and nonathletes. Journal of Athletic Training, 40, 47-51.

Selby, R., Weinstein, H.M., \& Bird, T.S. (1990). The health of university athletes: Attitudes, behaviors, and stressors. Journal of American College Health, 39, 11-18.

Shankar, P.R., Fields, S.K., Collins, C.L., Dick, R.W., \& Comstock, R.D. (2007). Epidemiology of high school and collegiate football injuries in the United States 2005-2006. American Journal of Sports Medicine, 35, 1295-1303.

Silvers, H. (2009). Play at your own risk: Sport and the injury epidemic. ACL injury prevention in the female athlete. A paper presented at the NCAA Scholarly Colloquium, Washington, D.C., January 13.

Smith, A.M., Stuart, M.J., Wiese-Bjornstal, D.M., \& Gunnon, C. (1997). Predictors of injury in ice hockey players: A multivariate, multidisciplinary approach. American Journal of Sports Medicine, 25(4), 500-507.

Sokolove, M. (2008). Warrior girls: Protecting our daughters against the injury epidemic in women's sports. New York: Simon \& Schuster.

Steiner, H., Pyle, R.P., Brassington, G.S., Matheson, G., \& King, M. (2003). The College Health Related Information Survey (C.H.R.I.S.-73): A screen for college student athletes. Child Psychiatry and Human Development, 34, 97-109.

Storch, E.A., Storch, J.B., Killiany, E.M., \& Roberti, J.W. (2005). Self-reported psychopathology in athletes: A comparison of intercollegiate student-athletes and non-athletes. Journal of Sport Behavior, 28, 86-98.

Strawbridge, M. (2001). Current activity patterns of women intercollegiate athletes of the late 1960's and 1970's. Women in Physical Activity Journal, 10, 55-68.

Sundgot-Borgen, J. (1994). Risk and trigger factors for the development of eating disorders in female elite athletes. Medicine and Science in Sports and Exercise, 26, 414-419.

Sundgot-Borgen, J., \& Torstveit, M.K. (2004). Prevalence of eating disorders in elite athletes is higher than in the general population. Clinical Journal of Sport Medicine, 14, $25-32$.

Turner, A.P., Barlow, J.H., \& Heathcote-Elliott, C. (2000). Long term health impact of playing professional football in the United Kingdom. British Journal of Sports Medicine, 34, 332-337.

Twincities.com. (2004). Interview with Lindsay Whalen. Retrieved March 23, 2004 from http://www.twincities.com/

United States Department of Health \& Human Services (USDHHS). (2008). Physical activity guidelines advisory committee report. Retrieved February 6, 2009 from http:// www.health.gov/paguidelines/

Watson, J.C. (2005). College student-athletes' attitudes toward help-seeking behavior and expectations of counseling services. Journal of College Student Development, 46, 442-449.

Wiese-Bjornstal, D.M. (2003). From skinned knees and Pee Wees to menisci and masters: Developmental sport injury psychology. In M.R. Weiss (Ed.), Developmental sport and exercise psychology: A lifespan perspective (pp. 525-568). Morgantown, WV: Fitness Information Technology.

Wiese-Bjornstal, D.M. (2000, March). Playing with injury. In D.M. Wiese-Bjornstal (Ed.), "Counseling Your Athletes" column. Athletic Therapy Today, 5(2), 60-61.

Wiese-Bjornstal, D.M. (2001, May). In the mood. In D.M. Wiese-Bjornstal (Ed.), "Counseling Your Athletes" column. Athletic Therapy Today, 6(3), 38-39.

Wiese-Bjornstal, D.M. (2002a, September). Pain, no gain. In D.M. Wiese-Bjornstal (Ed.), "Counseling Your Athletes" column. Athletic Therapy Today, 7(5), 56-57. 
Wiese-Bjornstal, D.M. (2002b, March). To play or not to play? That is the question. In D.M. Wiese-Bjornstal (Ed.), "Counseling Your Athletes" column. Athletic Therapy Today, 7(2), 24-26.

Wiese-Bjornstal, D.M. (2004). Psychological responses to injury and illness. In G.S. Kolt \& M.B. Andersen (Eds.), Psychology in the physical and manual therapies (pp. 2138). Edinburgh: Churchill Livingstone.

Wiese-Bjornstal, D.M. (2008, Fall). A sport psychology perspective: True confessions of a Warrior Girl turned mild-mannered soccer mom. Tucker Center Newsletter. Retrieved February 15, 2009 from http://cehd.umn.edu/tuckercenter/newsletter/2008-fall/feature.htm

Wiese-Bjornstal, D.M., Heniff, C.B., \& Henert, S. (1998). A comparison of life event stress, weekly hassles, and mood disturbance between injured and uninjured university athletes. Unpublished manuscript, University of Minnesota, Minneapolis.

Wiese-Bjornstal, D.M., Smith, A.M., \& LaMott, E.E. (1995). A model of psychologic response to athletic injury and rehabilitation. Athletic Training. Sports Health Care Perspectives, 1(1), 17-30.

Wiese-Bjornstal, D.M., Smith, A.M., Shaffer, S.M., \& Morrey, M.A. (1998). An integrated model of response to sport injury: Psychological and sociological dynamics. Journal of Applied Sport Psychology, 10, 46-69.

Williams, J.M., \& Andersen, M.B. (1998). Psychosocial antecedents of sport injury: Review and critique of the stress and injury model. Journal of Applied Sport Psychology, 10(1), 5-25.

Williamson, D.A., Netemeyer, R.G., Jackman, L.P., Anderson, D.A., Funsch, C.L., \& Rabalais, J.Y. (1995). Structural equation modeling of risk factors for the development of eating disorder symptoms in female athletes. The International Journal of Eating Disorders, 17, 387-393.

Wilson, G.S., Pritchard, M.E., \& Schaffer, J. (2004). Athletic status and drinking behavior in college students: The influence of gender and coping styles. Journal of American College Health, 52, 269-273.

Yang, J., Peek-Asa, C., Corlette, J.D., Cheng, G., Foster, D.T., \& Albright, J. (2007). Prevalence of and risk factors associated with symptoms of depression in competitive collegiate student athletes. Clinical Journal of Sport Medicine, 17(6), 481-487.

Zernicke, R. (2009). Play at your own risk: Sport and the injury epidemic. Paper presented at the NCAA Scholarly Colloquium, Washington, D.C., January 13. 